\title{
The Ultrastructure of the Radial Neuromuscular System of the Jellyfish Liriope tetraphylla (Hydrozoa, Trachymedusae): Implications in Crumpling Behavior
}

\author{
ELIANA SCEMES AND JOHN C. MCNAMARA ${ }^{1, *}$ \\ Departamento de Fisiologia Geral, Instituto de Biociências and ${ }^{1}$ Departamento de Fisiologia \\ e Biofísica, Instituto de Ciências Biomédicas, Universidade de São Paulo, 05508 SP, Brasil
}

\begin{abstract}
The ultrastructure of the radial neuromuscular system of the trachymedusa Liriope tetraphylla was examined to determine the morphological substrate underlying crumpling behavior-the folding of the margin into the subumbrellar cavity by radial muscle contraction. These contractions are produced by the four smooth muscle bands that run the length of the peduncle and extend over the subumbrellar surface to the margin, along the radii. Axons are present in the radial system and attain appreciable density at the base of insertion of the peduncle; contact between this radial nerve net and the inner nerve ring may occur at the margin. Gap junctions were not encountered within the ectodermal radial system. These various observations are discussed with respect to the control of crumpling in this and other species of hydromedusae.
\end{abstract}

\section{Introduction}

Structural differences apparent in the anatomy of the central nervous system of related species are often associated in a causal way with manifested behavioral differences.

The Cnidaria are among the first metazoans to possess identifiable neural elements. Members of all classes possess subepithelial networks of bipolar or multipolar neurons, which exhibit chemical or electrical synapses. In certain taxa, these elements are concentrated into well-defined tracts or ganglion-like structures (see Passano, 1982; Spencer and Schwab, 1982, for reviews and references).

The cnidarian nervous system may be considered structurally simple, but that does not necessarily mean that it is functionally simple, particularly given the so-

\footnotetext{
Received 14 September 1990; accepted 25 September 1991.

* Present address: Departamento de Biologia, FFCL-RP, Universidade de São Paulo, Ribeirão Preto, 14049 SP, Brasil.
}

phisticated behavioral repertoire of many cnidarian species (see Donaldson et al., 1980; Roberts and Mackie, 1980; Mackie and Meech, 1985).

Although not all species of hydromedusae exhibit precisely the same behaviors, recognizable individual components, such as swimming, feeding (pointing), crumpling, turning, righting, and tentacle posture have been defined (Hyman, 1940; Mackie, 1975; Mackie and Singla, 1975). The morphological substrate involved in these behaviors in different species, are not necessarily the same. For example, crumpling - a protective response involving contraction of the radial musculature and infolding of the margin into the subumbrellar cavity-is effected by one of at least three pathways: (1) through an entirely epithelial pathway (epithelial conduction), whereby excitation spreads from the ectoderm of the exumbrella into the endoderm, at the margin, and then to the effectors of the response (Mackie, 1975); (2) through the involvement of neurons, which presumably act as an intermediate link between epithelial conduction and radial muscle activation (Mackie and Passano, 1968; Spencer, 1975; King and Spencer, 1981); or (3) by a pathway composed entirely of neurons (von Carolsfeld, 1976).

In most hydromedusae so far investigated, the ability of the exumbrellar epithelium to propagate action potentials (epithelial conduction) has been attributed to the presence of gap junctions, which are abundant in their tissues (Mackie, 1975; Laat $e t$ al., 1980; McDowall and Grimmelikhuijzen, 1980; Spencer and Satterlie, 1980; Westfall et al., 1980; Dunlap et al., 1987; Frazer et al., 1987).

Liriope tetraphylla Chamisso and Eysenhardt, 1821, is a trachymedusa, the most conspicuous behavior of which is swimming. This occurs as irregular bursts of pulsations interrupted by periods of quiescence (Scemes and Freitas, 1989). Its other distinct behaviors are pointing and crum- 
pling. Pointing is produced by asymmetrical contractions of the radial muscles, and occurs frequently, even in the absence of a food stimulus. Crumpling is produced by simultaneous contraction of the four radial muscle bands and of the muscles in the peduncle, and is only infrequently observed. Attempts to induce crumpling through mechanical or electrical stimulation of the exumbrellar epithelium have not been successful (Scemes and Mendes, 1986, 1988; Scemes and Freitas, 1989), suggesting that $L$. tetraphylla lacks epithelial conduction, at least within the ectoderm (Scemes and Mendes, 1986; Scemes and Freitas, 1989). However, when this jellyfish is exposed to cholinergic agents, crumpling behavior does occur (Scemes and Mendes, 1986, 1988), and the involvement of a neuronal pathway in the crumpling behavior of L. tetraphylla thus has been surmised.

In the present paper, we describe the fine structure of the radial neuromuscular system of Liriope tetraphylla and provide ultrastructural support for the existence of the putative neuronal pathway involved in the control of crumpling behavior in this species.

\section{Materials and Methods}

Specimens of Liriope tetraphylla were collected by plankton net from the São Sebastião Channel, São Paulo State, Brazil.

The jellyfish were anesthetized with artificial seawater containing $200 \mathrm{mM} \mathrm{MgCl}_{2}$. Body tissue was dissected in ice-cold fixative under a stereomicroscope, and fragments of the radial system were immersed (for $2.5 \mathrm{~h}$ at $4^{\circ} \mathrm{C}$ ) in a primary fixative containing $0.25 \mathrm{M}$ glutaraldehyde and $0.1 M$ paraformaldehyde, buffered with $0.2 M$ sodium cacodylate, in diluted artificial seawater (Pantin, 1948). The fragments were washed three times, for $5 \mathrm{~min}$ each, in $0.2 M$ cacodylate-buffered artificial seawater and postfixed in $0.2 \mathrm{M}$ cacodylate-buffered artificial seawater containing $1 \%$ osmium tetroxide. After dehydration in a series of cold graded ethanols, the material was passed through propylene oxide, infiltrated overnight in a propylene oxide-Araldite mixture (1:1), and embedded in Araldite.

Thick sections $(0.5 \mu \mathrm{m})$ were stained with equal parts of $1 \%$ methylene blue and $1 \%$ toluidine blue in $1 \%$ aqueous borax and analyzed and photographed with a Zeiss photomicroscope. Silver-gold, thin sections (50-80 $\mathrm{nm}$ ) were contrasted with uranyl acetate and lead citrate and were examined in a JEOL $100 \mathrm{C}$ electron microscope at an accelerating voltage of $80 \mathrm{kV}$.

\section{Results}

Micro-anatomy of the neuromuscular system of Liriope tetraphylla

The anatomy of Liriope tetraphylla is summarized in Figure 1. The neuromuscular system of the subumbrellar surface consists of a radial system and a circular system. The radial muscular system is composed of four muscle

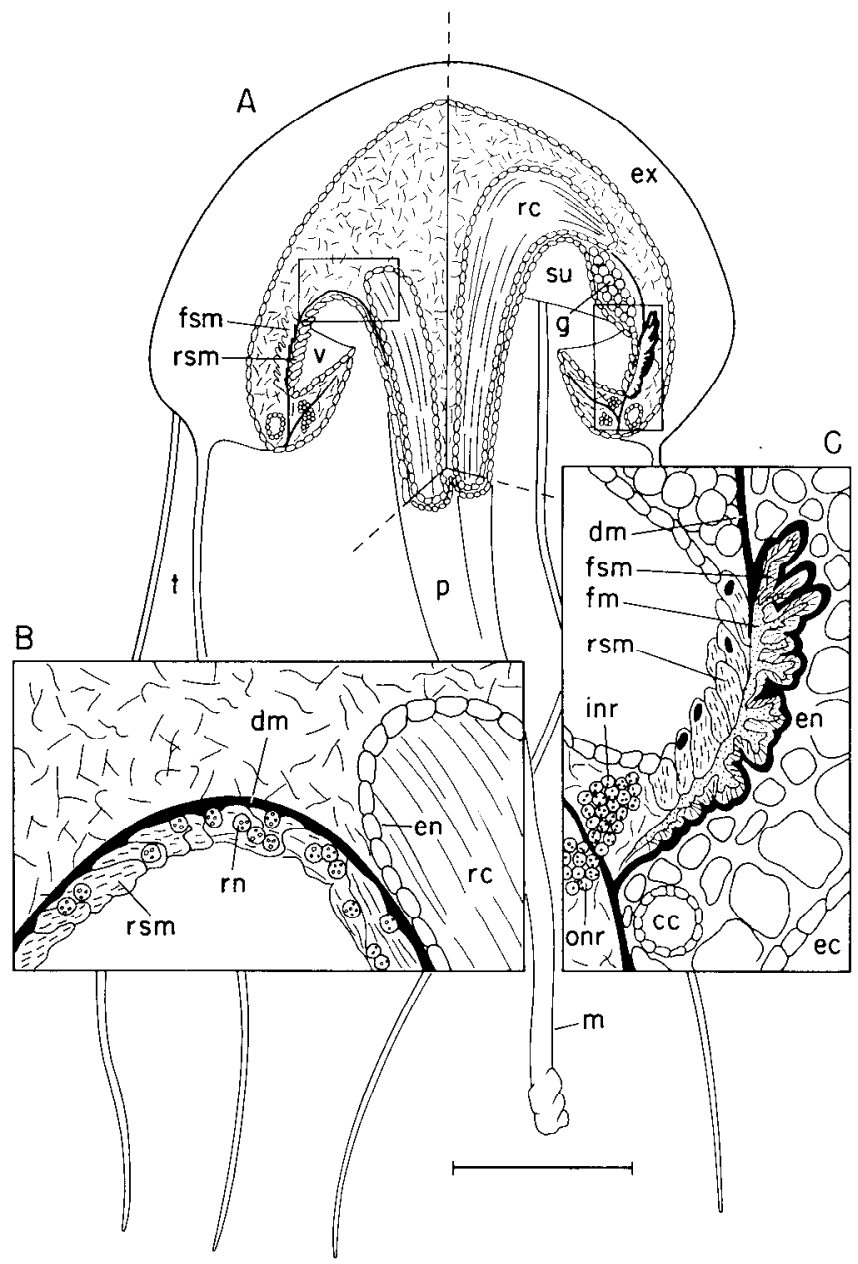

Figure 1. (A) Schematic transection through the body wall of the trachymedusa Liriope tetraphylla showing the disposition of the radial neuromuscular system and radial canals. (B) Detail of insertion of the peduncle into the subumbrella, showing radial smooth muscles, radial canal, and network of ectodermal neurons. (C) Detail of radial smooth muscles and folded, striated swimming muscles at the margin showing the relationship of the various structures to the mesoglea, inner and outer nerve rings, and circular canal. Circular canal (cc), dense mesoglea (dm), ectoderm (ec), endoderm (en), exumbrella (ex), fibrous mesoglea (fm), folded, striated swimming muscle (fsm), gonad ( $\mathrm{g}$ ), inner nerve ring (inr), manubrium (m), outer nerve ring (onr), peduncle ( $p$ ), radial canal (rc), radial ectodermal neurons $(\mathrm{rn})$, radial smooth muscle ( $\mathrm{rsm})$, subumbrella (su), tentacles (t), and velum (v). Scale bar: (A) $=0.5 \mathrm{~cm},(B)$ and $(\mathrm{C})=0.5 \mathrm{~mm}$.

bands. These run from the mouth, along the manubrium and peduncle, out over the subumbrellar surface, where they overlie the radial canals, to the margin.

In the manubrium (0.33 $\mathrm{mm}$ diameter) (Fig. 2$)$, the four ectodermal muscle bands, which in cross section measure $24 \mu \mathrm{m}$ high by $100 \mu \mathrm{m}$ wide, are diametrically opposed and occupy almost the entire manubrium wall. The endoderm is reduced to a single cell layer in these regions, but thickens considerably in the areas between adjacent muscle bands. At the insertion of the peduncle into the subumbrella, the four muscle 

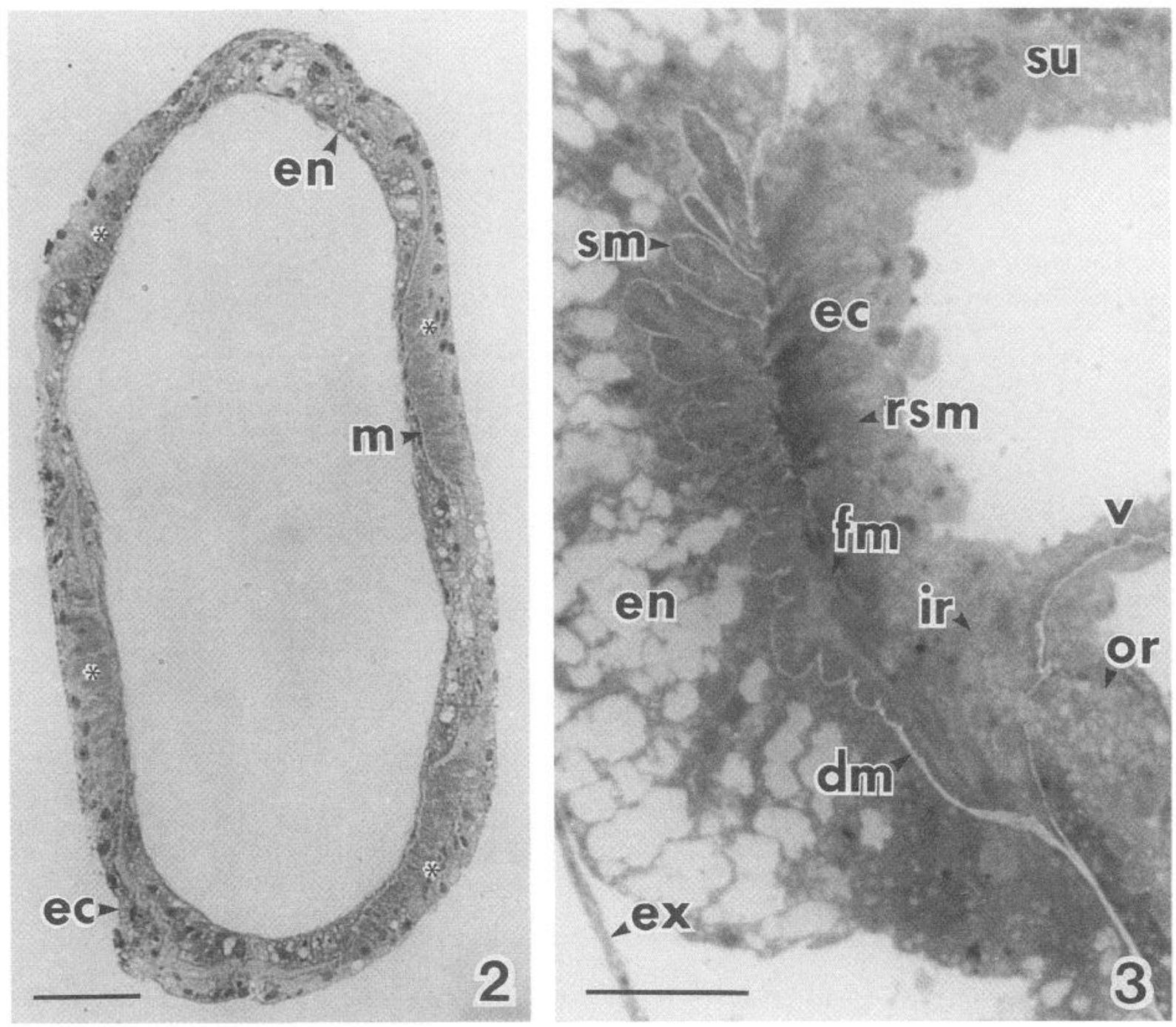

Figure 2. Light micrograph of a transverse section through the manubrium showing ectoderm (ec), endoderm (en), mesoglea (m), and four bands of ectodermal smooth muscle cells (*). Scale bar $=50 \mu \mathrm{m}$.

Figure 3. Light micrograph of a transverse section through the radial system at the margin showing ectodermal, radial smooth muscle cells (rsm), striated swimming muscle cells (sm), inner nerve ring (ir), outer nerve ring (or), dense mesoglea ( $\mathrm{dm}$ ), fibrous mesoglea ( $\mathrm{fm}$ ), exumbrella (ex), subumbrella (su), velum (v), and ectodermal (ec) and endodermal cells (en). Scale bar $=30 \mu \mathrm{m}$.

bands surround the peduncle, subsequently diverging to follow each of the four radial canals out to the umbrella margin.

The circular neuromuscular system consists of the striated, circular muscle layer which lines the subum- brellar surface, and the inner and outer nerve rings which lie at the margin. The striated muscle layer exhibits extensive infolding where it meets the radial neuromuscular system, from which it is separated by the mesoglea (Fig. 3).

Figure 4. Electron micrograph of a transverse section through the ectodermal smooth muscle layer in the manubrium. The filamentous mesoglea $(\mathrm{m})$ and areas of desmosomal contact (d) between adjacent myofibrils are visible. Scale bar $=1 \mu \mathrm{m}$.

Figure 5. Area of synaptic contact (s) between two ectodermal neurons in the peduncle, showing a dense cored vesicle $(\mathrm{dv})$ and a mitochondrion $(\mathrm{m})$. Scale bar $=300 \mathrm{~nm}$.

Figure 6. Transverse section of a neuron (n) juxtaposed to ectodermal smooth muscle cell (m). Scale $\mathrm{bar}=0.8 \mu \mathrm{m}$. Insert: clear vesicles from ectodermal neuron. Scale bar $=140 \mathrm{~nm}$. 

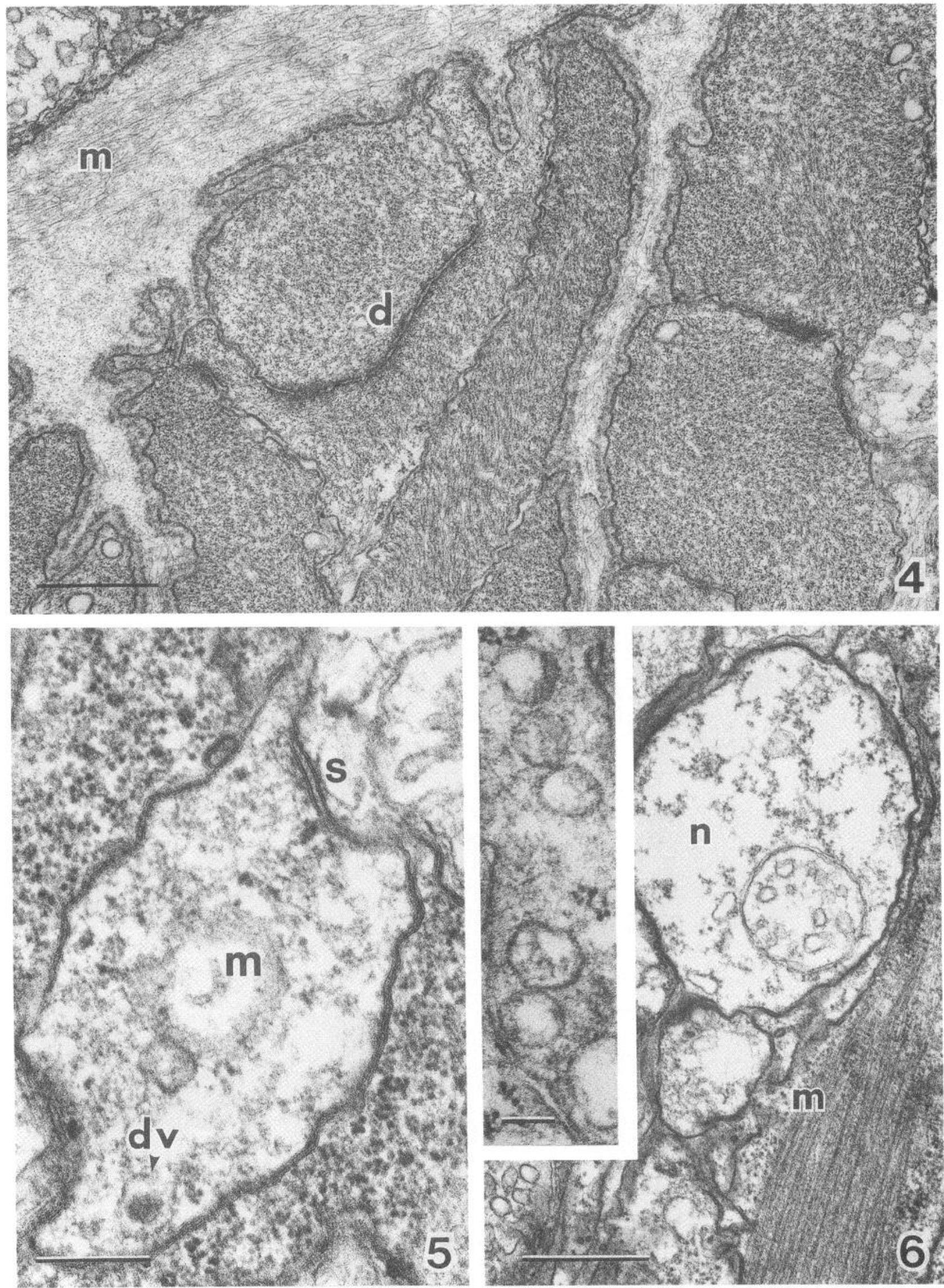

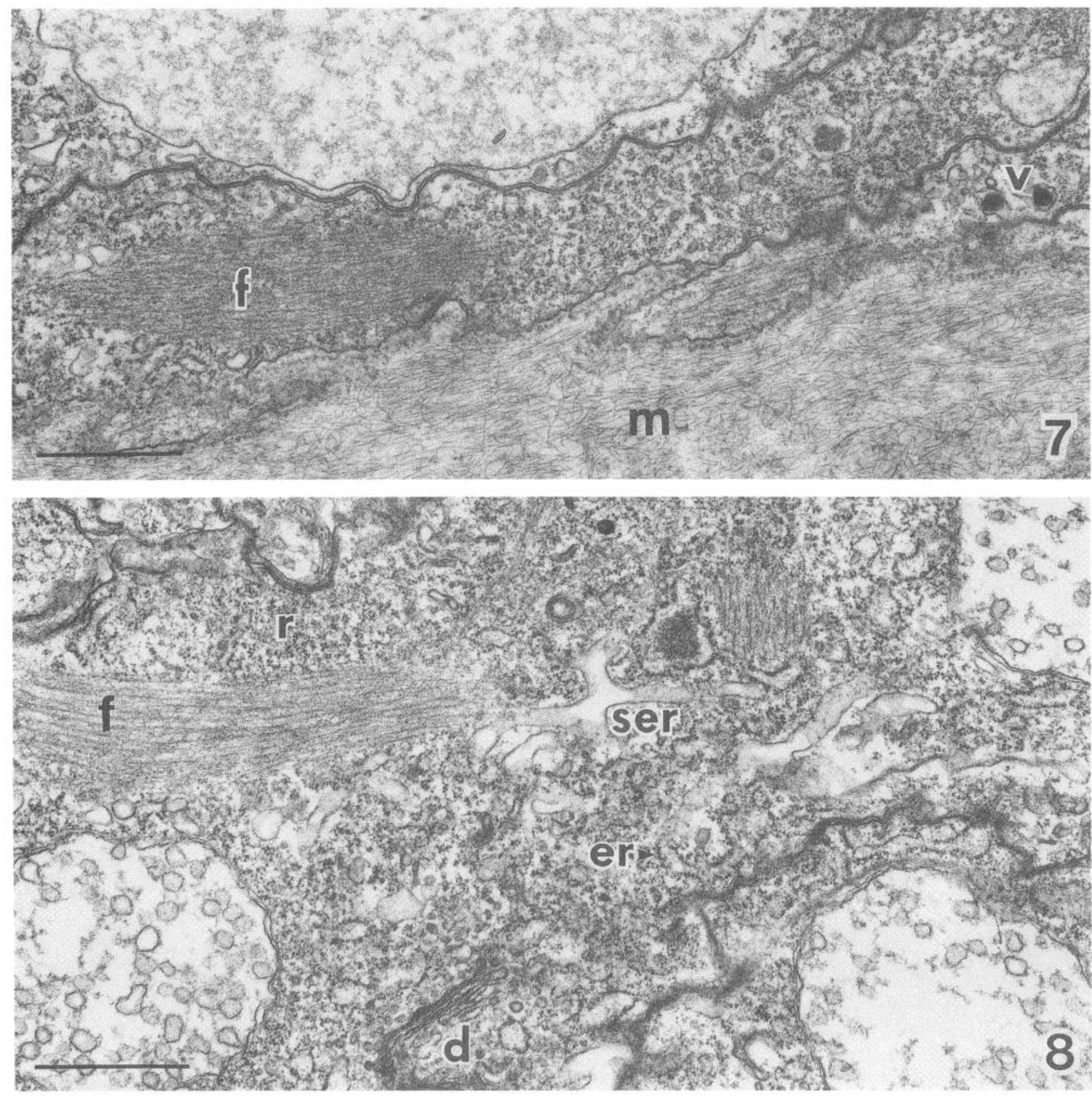

Figure 7. Endodermal myoepithelial cells showing myofilaments (f), vesicles (v) and the filamentous mesoglea $(\mathrm{m})$. Scale bar $=1 \mu \mathrm{m}$.

Figure 8. Endodermal myoepithelial cell showing extensive myofilament bundles (f), areas of rough (er) and smooth (ser) endoplasmic reticulum, ribosomes ( $\mathrm{r}$ ) and a Golgi body (d). Scale bar $=1 \mu \mathrm{m}$.

Figure 9. Umbrella margin showing part of an ectodermal smooth muscle cell (ec), striated swimming muscle (sm), mesoglea (m), and radial neurons (n). Scale bar $=1.5 \mu \mathrm{m}$.

Figure 10. Dense, afilamentous mesoglea (m) separating the endodermal cell layer (en) from the swimming muscles (sm). Scale bar $=1.5 \mu \mathrm{m}$. Insert: gap junction between adjacent endodermal cells. Scale bar $=50$ $\mathrm{nm}$. 

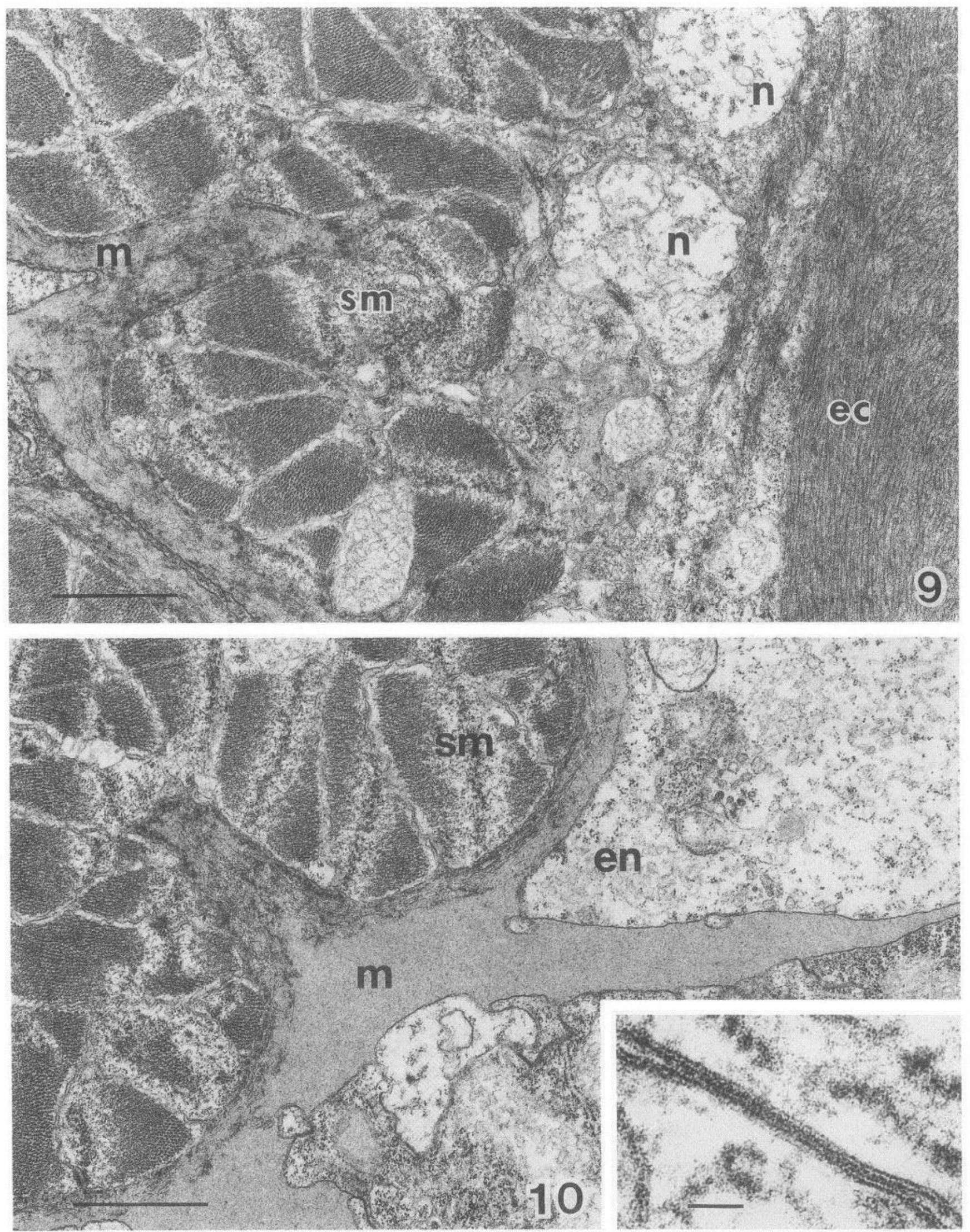

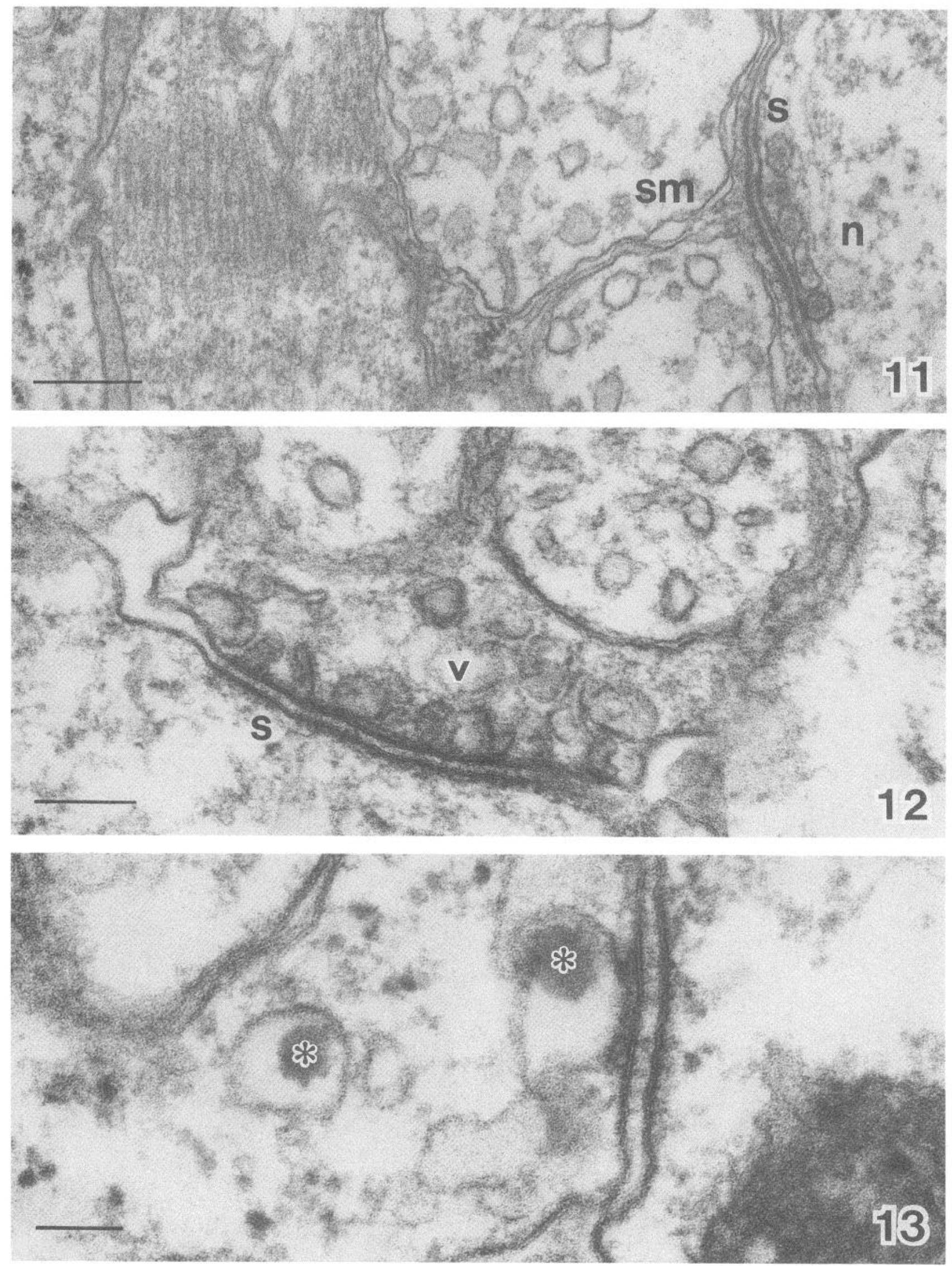


\section{Ultrastructure}

Three types of muscle cells are found in the manubrium and peduncle: two are located within the ectoderm, the third is restricted to the endoderm.

The predominant muscle type in the ectodermal muscle bands is a smooth muscle cell that measures 2 to $4 \mu \mathrm{m}$ in width by at least 10 to $20 \mu \mathrm{m}$ in length (Fig. 2). These cells are connected by desmosome-like structures and form a well developed layer (Fig. 4), the basal surface of which interdigitates extensively with the mesoglea. Their myofilaments are oriented parallel to the longitudinal axis of the manubrium and peduncle.

Axons, 0.4 to $1.5 \mu \mathrm{m}$ in diameter, containing either dense cored vesicles of approximately $140 \mathrm{~nm}$ diameter (Fig. 5) or clear vesicles of about $200 \mathrm{~nm}$ diameter (Fig. 6), are interspersed between the muscle cells. While these axons are found throughout the manubrium and peduncle, presumably forming a diffuse nerve net, they are particularly dense at the base of the peduncle around which they appear to form a ring-like structure. Although interneuronal, chemical synapses (Fig. 5) are common, neuromuscular synapses were never observed between the neurons and smooth muscle cells.

The second type of ectodermal muscle cell was encountered only infrequently. It is distributed from the mouth throughout the manubrium and peduncle and is characterized by a spheroidal aggregation of myofilaments (3.5-5 $\mu \mathrm{m}$ diameter) surrounded by an electron-lucent cytoplasm. These myoepithelial cells lie close to the external surface of the ectoderm, their innermost surface being apposed to the underlying layer of ectodermal smooth muscle. The functional relevance of this cell type is not clear, but they could be myoblasts, or ectodermal smooth muscle cells undergoing lysis.

The endodermal myoepithelial cells are $1.3 \mu \mathrm{m}$ in diameter and at least $17 \mu \mathrm{m}$ long, and contain 6- to 8-nm diameter myofilaments that are oriented perpendicularly to the long axis of the manubrium. These cells also contain clear vesicles and dense cored vesicles of about $160 \mathrm{~nm}$ diameter, mitochondria, smooth and rough endoplasmic reticulum, ribosomes, and Golgi complexes (Figs. 7, 8). This endodermal muscle layer is well developed in those areas where the four ectodermal muscle bands do not predominate (Fig. 2). The existence of an endodermal nerve net is questionable, because any putative axon profiles may, in fact, represent transections of these endodermal myoepithelial cells.
The smooth muscle cells and neurons of the radial neuromuscular system of the manubrium and peduncle lie parallel to the radial canals that connect the manubrium to the circular canal (Fig. 1). Neuromuscular synapses were not observed within the radial system, but their existence cannot be refuted. No evidence was found for gap junctions, between either neurons or muscle cells, within the entire radial pathway. Where the radial and circular muscles overlap, they are separated by a fibrous layer, and the underlying, striated circular muscle is heavily infolded (Figs. 3, 9, 10). Axon profiles are very evident in the fibrous layer that separates the two muscle types (Fig. 9), and these axons, together with the muscle, come into close proximity with the inner nerve ring at the margin.

These ectodermal layers are separated from the endoderm by a layer of electron-dense mesoglea that apparently lacks filaments (Figs. 3, 10). Many gap junction-like structures (gap of $3 \mathrm{~nm}$ ), and areas exhibiting an intercellular space of fixed width $(10 \mathrm{~nm})$, were observed between the endodermal cells (Fig. 10).

The striated muscle cell layer, which covers the entire subumbrellar surface of the bell, is innervated by neurons of the inner nerve ring (Fig. 11). These contacts are characterized by a synaptic cleft $(15 \mathrm{~nm})$ that separates plasmalemmae underlain by electron-dense plaques of finely filamentous material and by the presence of spherical to irregular, clear vesicles of about $75 \mathrm{~nm}$ diameter. Gap junction-like structures were not observed between the striated muscle cells. If such junctions do exist within this tissue layer, they are far less frequent than those seen within the endodermal layer (Fig. 10).

Synaptic contacts between the neurons within both the inner and outer nerve rings are characterized by a synaptic cleft of 20-23 nm and irregular to roughly spherical vesicles. In the inner nerve ring, these are clear and about $90 \mathrm{~nm}$ in diameter (Fig. 12); in the outer nerve ring, the vesicles are dense cored and about $140 \mathrm{~nm}$ in diameter (Fig. 13). Gap junctions were not observed within the nerve rings. In the inner nerve ring, single neurons were observed to make at least three neuro-neuronal synaptic contacts of the chemical type, all at the same locus.

\section{Discussion}

Crumpling behavior was originally defined as the infolding of the margin into the subumbrellar cavity and the subsequent cessation of swimming activity (Hyman,

Figure 11. Synaptic contact (s) betwcen ncuron (n) and striated muscle cell (sm) from subumbrellar surface. Scale bar $=300 \mathrm{~nm}$.

Figure 12. Synaptic contact (s) between two neurons from the inner nerve ring showing irregular clear vesicles (cv). Scale bar $=200 \mathrm{~nm}$.

Figure 13. Synaptic contact between two neurons from the outer nerve ring showing dense cored vesicles (*). Scale bar $=100 \mathrm{~nm}$. 
1940). In the species so far investigated, the main effectors of this behavior are the radial muscle systems of the peduncle and subumbrella and the longitudinal muscles of the tentacles. That the same effectors of crumpling act in L. tetraphylla is suggested by the high degree of development of the longitudinal, ectodermal muscle bands of the manubrium and peduncle and the radial muscle bands on the subumbrella.

Crumpling in hydromedusae appears to be coordinated by at least three pathways: one entirely dependent on epithelial conduction, one that employs both epithelial and neuronal substrates, and the third, an entirely neuronal pathway.

The purely epithelial pathway has been proposed for Stomotoca atra (Mackie, 1975). In this species, electrical stimulation of the exumbrella evokes action potentials that radiate over the exumbrella ectoderm and spread by way of the endodermal lamella to the subumbrella, where they elicit contraction of the radial muscles. Stimulation of the exumbrella also directly inhibits the animal's swimming rhythm. Significantly, gap junctions with a gap space of 3 to $4 \mathrm{~nm}$, have been found within the exumbrella epithelium of $S$. atra (Mackie and Singla, 1975).

Crumpling in $S$. atra can also be induced by extracts of the predatory hydromedusa Aequorea aequorea (Schwab, 1977). But the rcsponse so cvoked differs from that elicited by electrical or mechanical stimulation, in that the exumbrella ectoderm is not involved, and tetanic contractions of the peduncle are absent. These differences imply that crumpling in this species can be achieved by at least two pathways, one of which remains unknown.

In contrast, crumpling in Sarsia tubulosa (Mackie and Passano, 1968), Proboscidactyla flavicirrata (Spencer, 1975), and Polyorchis penicillatus (King and Spencer, 1981) involves neuronal elements that are thought to provide an intermediate link between epithelial conduction (sensory element) and radial muscle contraction (effector). Specifically, the absence of temporal correlation between radial muscle potentials and endodermal pulses in Polyorchis penicillatus, prompted King and Spencer (1981) to propose that epithelial pulses do not excite the radial muscles directly, but rather do so by way of the inner or outer nerve rings. In $P$. penicillatus, cells in the radial muscle bands, which are organized in the same way as those described here for $L$. tetraphylla, are connected laterally by desmosomes. Gap junctions are also present but rare (Spencer, 1979). While direct communication between the ectodermal epithelium and neurons might occur at the margin, specialized junctions have not been encountered (Spencer, 1979).

Conversely, the olindiad Epiretmus typus does not possess an excitable exumbrella or endodermal lamella (von Carolsfeld, 1976), and electrical or mechanical stimulation of these structures does not result in muscle contraction. Crumpling, however, can be triggered by electrical or me- chanical stimulation of the tentacles; this behavior is entirely dependent on the integrity of the margin, where neuronal elements are present, and is prevented by high concentrations of magnesium.

Further, the olindiad Gonionemus vertens does not possess an excitable exumbrella and does not crumple, yet gap junctions are common in its exumbrellar epithelium, subumbrellar lamella, and endoderm of the radial canals, much as is found in other species in which epithelial conduction has been described (von Carolsfeld, 1976). Clearly, causal relationships between either the presence of an excitable epithelium and the manifestation of crumpling behavior, or the presence of gap junctions and excitability, cannot always be established.

In L. tetraphylla, the only specialized intercellular contacts observed between the radial muscle cells were desmosomes (Fig. 4); gap junctions are apparently absent. This observation suggests that excitation of these muscles is achieved exclusively by way of chemical synapses, although the possibility of limited electrical coupling through very small gap junctions cannot be excluded. The absence of identified neuromuscular synapses is problematic, but the abundance of neuronal profiles with either clear or dense cored vesicles suggests that such synapses must be present.

Epithelial conduction in the exumbrellar epithelium is probably not involved in the crumpling response of $L$. tetraphylla, because neither electrical nor mechanical stimulation of the exumbrella induces radial muscle contraction (Scemes, 1985; Scemes and Freitas, 1989). Furthermore, although the endodermal cells are connected by gap junctions, and so are presumably electrically coupled, any action potentials generated in this layer would be prevented from spreading to the ectodermal muscles and nerves by the presence of the dense mesoglea that separates the tissue layers. Transmesogleal, epithelial bridges ( $c f$., Mackie and Singla, 1975; Spencer, 1979) were not encountered. In general, gap junction-like structures were observed only in the endodermal cell layer and were not found between muscle and nerve cells. Symmetrical contraction of the radial muscles and retraction of the tentacles and manubrium (i.e., crumpling) can, however, be induced in L. tetraphylla pharmacologically. Application of muscarinic antagonists (atropine) and nicotinic agonists (nicotine) to whole animal preparations induces the crumpling response (Scemes and Mendes, 1986, 1988), and under these conditions, with or without mechanical stimulation, exumbrellar potentials are not observable (Scemes, unpub. data).

As noted above, the exumbrellar epithelium in Polyorchis penicillatus has a sensory function, furnishing inputs to the neural elements that trigger the contraction of the crumpling effectors. Given that stimulation of the exumbrella elicits partial crumpling, while stimulation of the margin leads to a full crumpling response, King and 
Spencer (1981) proposed that radial muscle contraction in $P$. penicillatus is achieved either through the nerve rings (the marginal pathway) or through the radial nerves in the peduncle (the apical pathway).

The marginal pathway, particularly the inner nerve ring, is probably involved in the crumpling behavior of L. tetraphylla, based on both morphological and physiological observations. The radial nerves and inner nerve ring are in close proximity at the margin, providing for possible interaction. Furthermore, electrophysiological studies have shown that crumpling in L. tetraphylla is associated initially with an increase in swimming activity and then, as crumpling persists, by inhibition (Scemes and Freitas, 1989). Whether the interactions between the radial and circular systems are uni- or bidirectional requires further investigation. The abundance of chemical synapses in both nerve rings, and specifically the presence of polysynaptic contacts within the inner nerve ring, suggest that highly complex neuronal interactions are possible.

An apical pathway, of the type suggested by King and Spencer (1981) for Polyorchis penicillatus, may also be present in L. tetraphylla, given the abundance of neurons in what may be a nerve ring at the base of the peduncle. Such a nerve ring may serve to effect the synchronous contraction of the four radial muscle bands that are necessary for crumpling.

Clearly, electrophysiological studies are required to elucidate the mechanisms underlying crumpling behavior in hydromedusae, and to reveal how the various conducting systems interact to modify observed behavioral output. The data obtained here, for L. tetraphylla, suggest that crumpling is effected by the nervous system through chemical synapses, implying the existence of a functionally complex nervous system despite the apparent morphological simplicity. Comparative studies will be valuable in establishing the degree of participation of the epithelial and neuronal elements involved in the behavioral repertoire of the Cnidaria, and will provide much needed insight into the means by which different mechanisms have evolved to bring about essentially similar behaviors.

\section{Acknowledgments}

The authors thank Professor Paulo A. Abrahamsohn of the Electron Microscopy Sector, Department of Histology and Embryology, University of São Paulo for access to electron microscopical facilities, and Moises Alexandre da Motta for collecting biological material at the Center for Marine Biology, University of São Paulo in São Sebastião. Photographic work by Francisco Abós Salvador, and particularly the line drawing by Dr. Lelio Favaretto, are gratefully acknowledged. This study was partially financed by the Conselho Nacional de Desenvolvimento Científico e Tecnológico (303982/86-8).

\section{Literature Cited}

Donaldson, S., G. O. Mackie, and A. Roberts. 1980. Preliminary observations on escape swimming and giant neurons in Aglantha digitale (Hydrozoa, Trachylina). Can. J. Zool. 58: 549-552.

Dunlap, K., K. Takeda, and P. Brehm. 1987. Activation of a calciumdependent photoprotein by chemical signaling through gap junctions. Nature 325: 60-62.

Frazer, S. E., C. R. Green, H. R. Bode, and N. B. Gilula. 1987. Selective disruption of gap junctional communication interferes with a patterning process in Hydra. Science 237: 49-55.

Hyman, L. H. 1940. Observations and experiments on the physiology of medusae. Biol. Bull. 79: 282-296.

King, M. G., and A. N. Spencer. 1981. The involvement of nerves in the epithelial control of crumpling behaviour in a hydrozoan jellyfish. J. Exp. Biol. 94: 203-218.

Laat, S. W., L. G. Tertoolen, and C. J. Grimmelikhuijzen. 1980 . No junctional communication between epithelial cells in $\mathrm{Hydra}$. Nature 288: $711-713$.

Mackie, G. O. 1975. Neurobiology of Stomotoca. II. Pacemakers and conduction pathways. J. Neurobiol. 6: 357-378.

Mackie, G. O., and R. W. Meech. 1985. Separate sodium and calcium spikes in the same axon. Nature 313: 791-793.

Mackie, G. O., and L. M. Passano. 1968. Epithelial conduction in hydromedusae. J. Gen. Physiol. 52: 600-621.

Mackie, G. O., and C. L. Singla. 1975. Neurobiology of Stomotoca. I. Action systems. J. Neurobiol. 6: 339-356.

McDowall, A. W., and C. J. Grimmelikhuijzen. 1980. Intercellular junctions in nerve-free Hydra. Cell Tiss. Res. 209: 217-224.

Pantin, C. A. F. 1948. Notes on Microscopical Techniques for Zoologists, Cambridge University Press, London. 79 pp.

Passano, L. M. 1982. Scyphozoa and Cubozoa. Pp. 149-202 in Electrical Conduction and Behaviour in 'Simple' Invertebrates, G. A. B. Shelton, ed. Clarendon Press, Oxford.

Roberts, A., and G. O. Mackie. 1980. The giant axon escape system of a hydrozoan medusa, Aglantha digitale. J. Exp. Biol. 84: 303-318.

Scemes, E., and E. G. Mendes. 1986. Cholinergic mechanism in Liriope tetraphylla (Cnidaria, Trachymedusae). Comp. Biochem. Physiol. 83C: $171-178$.

Scemes, E., and E. G. Mendes. 1988. Pharmacology of the radial neuromuscular system of Liriope tetraphylla (Hydrozoa, Trachymedusae). Comp. Biochem. Physiol. 90C: 385-389.

Scemes, E., and J. C. Freitas. 1989. Electrophysiology of the swimming system of hydromedusae and the effects of atropine-induced crumpling. Braz. J. Med. Biol. Res. 22: 189-198.

Schwab, W. 1977. Electrical responses of Stomotoca atra induced by an extract of Aequorea aequorea. Nature 267: 701-702.

Spencer, A. N. 1975. Behavior and electrical activity in the hydrozoan Proboscidactyla flavicirrata. Il. The medusa. Biol. Bull. 149: 236-250.

Spencer, A. N. 1979. Neurobiology of Polyorchis. II. Structure of effector systems. J. Neurobiol. 10: 95-117.

Spencer, A. N., and R. A. Satterlie. 1980. Electrical and dye coupling in an identified group of neurons in a coelenterate. J. Neurobiol. 11: 13-19.

Spencer, A. N., and W. E. Schwab. 1982. Hydrozoa. Pp. 73-148 in Electrical Conduction and Behaviour in 'Simple' Invertebrates, G. A. B. Shelton, ed. Clarendon Press, Oxford.

von Carolsfeld, J. S. 1976. Contributions to hydromedusan neuroethology from a study on two olindiads, Gonionemus vertens (Agassiz, 1885) and Epiretmus typus (Bigelow, 1915). M. Sc. Thesis University of Victoria, Canada. $283 \mathrm{pp}$.

Westfall, J. A., J. C. Kinnamon, and D. E. Sims. 1980. Neuro-epitheliomuscular cell and neuro-neuronal gap junctions in $\mathrm{Iydra}$. J. Neurocytol. 9: 725-732. 